\title{
Chapter
}

\section{Cyclic Fatty Acids in Food: An Under-Investigated Class of Fatty Acids}

\author{
Augusta Caligiani and Veronica Lolli
}

\begin{abstract}
Cyclic fatty acids are an unusual class of minor fatty acids generally produced by bacteria and less frequently by plants. Among plants, the most known cyclic fatty acid is sterculic acid (9, 10-methyleneoctadecenoic acid) produced by Sterculia foetida. Bacteria (e.g., lactic acid bacteria) synthetize cyclopropane fatty acids, such as dihydrosterculic acid (9,10-methylene octadecanoic acid) and lactobacillic acid (11, 12 methylene octadecanoic acid), to strength their membrane, improving their resistance to environmental stress. Another class of cyclic fatty acids is omegacyclohexyl fatty acids, present in milk and probably produced by rumen bacteria. Cyclopropane and omega-cyclohexyl fatty acids have been recently found in bovine meat and dairy products, representing important foodstuffs in human diet. In this chapter, a review of literature data concerning the presence of cyclic fatty acids in foods, their metabolism in humans, and their potential bioactivity will be provided. The role of some cyclic fatty acids as molecular markers for food authenticity will also be highlighted.
\end{abstract}

Keywords: cyclopropane fatty acids, cyclohexyl fatty acids, food authentication, metabolism, bioactivity

\section{Introduction}

Lipids are water insoluble organic biomolecules that have several important biological functions within the cell, providing energy storage, participating in the formation of cell membranes, and exerting regulatory functions in transduction and signaling processes in multiple metabolic pathways [1]. Through these actions, dietary lipids can affect health, well-being, and the risk of developing disease, such as cardiovascular, inflammatory, and cognitive disorders, among many others [2].

The term lipid is known to describe fatty acids, their esters, and different lipophilic structures. Most dietary lipids consist of triglycerides, but there is also little amount of other lipid classes, such as phospholipids, present in the cell membranes of all food that we eat [3].

Fatty acids (FA) are carboxylic acids with an aliphatic chain of varying lengths: short chain $(C<6)$, medium chain $(6 C-12 C)$, long chain $(13 C-22 C)$, and very long chain $(\mathrm{C}>22)$. The most common chain length range for fatty acids is between $\mathrm{C} 12$ and $\mathrm{C} 22$ and they can be characterized by saturated and unsaturated (mono or poly) chains [4]. Most of the FA existing in nature have an even number of carbon 
atoms and linear hydrocarbon chains, although some of them, found primarily in bacteria, may contain branched or cyclic structures [5-7]. Fatty acids containing a carbocyclic unit naturally occur in specific genera of bacteria and in plants.

In some cases, alicyclic fatty acids, such as cyclopropane (CPFA) and omegacyclohexyl fatty acids (CHFA), are essential for cell survival, as they could affect the membrane fluidity that enables certain microorganisms to survive under extreme environmental conditions [8]. In plants, CPFA are usually minor components, where cyclopropene fatty acids are the most abundant. Sterculia foetida seed oil contains $65-78 \%$ of cyclopropene fatty acids (principally sterculic acid), suggested to have antifungal and enzyme inhibitor activities [9].

CPFA, especially dihydrosterculic (9,10-methylene-octadecanoic acid) and lactobacillic (11,12-methylene-octadecanoic acid) acids, have been identified as minor component of lipid profile in a wide range of milk and dairy products $[10,11]$ and, more recently, in meat and fish [12] representing important foodstuffs in human diet.

CPFA concentration ranges from 200 to $1000 \mathrm{mg} / \mathrm{kg}$ fat in dairy products and bovine meat [13]; therefore, their dietary intake may not be negligible, and their potential role in human health should not be underestimated.

However, due to their recent identification, so far CPFA have not been yet considered for their occurrence in humans, and several aspects related to their bioavailability and putative bioactivity as well as the bacterial strains producing CPFA in feeds and in which conditions still must be explored.

$\omega$-Cyclohexyl fatty acids (CHFAs), mainly cyclohexyl-undecanoic and tridecanoic acids, occur in several acido-thermophilic bacteria such as Alicyclobacillus acidocaldarius and can be biosynthesized by these bacteria species, even by adding cyclohexyl acid to the bacteria culture [11]. 11-cyclohexyl undecanoic acid was first isolated as a minor component of butter fat, then in sheep fat but it is almost certainly produced by bacteria in the rumen. 13-cyclohexyltridecanoic acid has been considered as a potential marker of ruminal acidosis in cow [11]. Recently, both $\omega$-cyclohexyl fatty acids, 11-cyclohexylundecanoic acid and 13-cyclohexyltridecanoic acid, were detected in meat fat, especially in bovine meat but not in pork and horse meat. Therefore, the presence of $\omega$-cyclohexyl fatty acids in foods was related to a ruminal origin and, combined with other fatty acids as branched chain fatty acids, could be proposed as marker of species [14].

This chapter reviews the literature data about the origin and natural occurrence of cyclic fatty acids, their presence in foods, especially in meat and dairy products, and their potential bioavailability and bioactivity in mammals. Finally, the application of some cyclic fatty acids as molecular markers for food authenticity will be provided.

\section{Cyclic fatty acids: natural occurrence and biosynthesis}

\subsection{Cyclopropane and cyclopropene fatty acids}

Cyclopropane fatty acids (CPFA), containing three carbon rings located at different sites of the fatty acid chain (Figure 1), occur widespread in several microorganisms as major lipid component [8] and in certain eukaryotes, including protozoa, fungi, and plants [9, 15]. Many cyclopropane-containing natural compounds have shown biological activity, and their presence in the cellular membrane seems to be related to its physicochemical properties [16]. However, the real significance of these compounds in their natural context is often less well known as well as their occurrence in higher animals. The major investigations which have been 


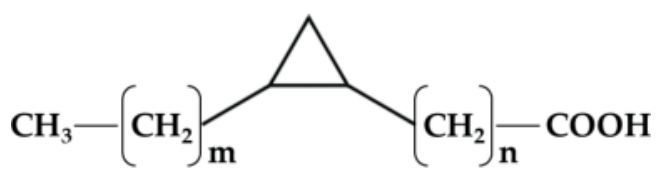

\begin{tabular}{|c|l|}
\hline $\mathbf{n}, \mathbf{m}$ & Common name \\
\hline 9,5 & lactobacillic acid \\
6,7 & dihydromalvalic acid \\
7,7 & dihydrosterculic acid \\
\hline
\end{tabular}

Figure 1.

Most commonly found cyclopropane fatty acids in bacteria.

published about their occurrence, biosynthesis, and their physiological role in the cellular membrane are described in more detail in the following paragraphs.

\subsubsection{Distribution}

A study of the fatty acid composition of Lactobacillus arabinosus first reported the isolation of lactobacillic acid (cis-11,12-methylene octadecanoic acid), a 19carbon cyclopropane analogue of cis-vaccenic acid, the major unsaturated fatty acid in L. arabinosus membrane [17].

Subsequently, lactobacillic acid and other cyclopropane fatty acids have been identified in a variety of microorganisms of both Gram-negative and Grampositive bacteria such as Lactobacilli, Streptococci, Enterobacteria, Clostridia, and Brucellaceae [18]. Some microorganisms contain cis-9,10-methylene octadecanoic acid (dihydrosterculic acid), derived from oleic acid, together with other isomers (C16 or C20 in chain length, as cis-9,10-methylene hexadecenoic acid).

CPFA are suggested to be associated with the occurrence of unsaturated fatty acids (UFA) in the bacterial membrane, generally palmitoleic (cis-9-hexadecenoic acid), cis-vaccenic (cis-11-octadecenoic acid), and oleic (cis-9-octadecenoic acid) acids [5]. Furthermore, it seems that they predominate at the end of the growth cycle of bacteria, when the majority of UFA are converted to cyclopropane fatty acids by the cyclopropane synthase [8].

Cyclopropane and the structurally related cyclopropene fatty acids have also been found in certain eukaryotes, including trypanosomatid protozoa and plants $[19,20]$.

In plants, cyclopropene fatty acids, such as sterculic acid (cis-9,10-methylene9-octadecenoic acid) and malvalic acid (cis-8,9-methylene-heptadecenoic acid), are distributed across several families, mainly in Sterculiaceae, Malvaceae, Bombacaceae, Tiliaceae, and Sapindaceae. It has been reported that cyclopropene fatty acids are often accompanied by smaller proportion of cyclopropanic fatty acids, such as dihydrosterculic and dihydromalvalic acids, which are the dihydro analogues of cyclopropene fatty acids [21].

Sterculia foetida is a tropical tree belonging to the Sterculiaceae family of order Malvales. Its seeds are rich in oil (55\% dry weight) and contain up to $78 \%$ of cyclopropenoid fatty acids (especially sterculic and malvalic acids), representing one of the highest source of carbocyclic fatty acids reported in nature [19].

CPFA were the major lipid component (42\%) in the seed oil of Litchi chinensis, belonging to Sapindaceae family. The CPFA fraction in Litchi chinensis seed oil mainly contains dihydrosterculic acid, and cis-7,8-methylenehexadecanoic acid, cis5,6-methylene-tetradecanoic acid, and cis-3,4-methylenedodecanoic acid in smaller amounts [22]. 
Malvalic, sterculic, and dihydrosterculic acids have also been detected in Baobab seeds oil from plant belonging to Adansonia species (Bombacaceae family) of Madagascar. Seed lipids containing CPFA are extensively consumed by humans, especially in those tropical areas $[19,23]$.

However, carbocyclic fatty acids seemed not to be confined to seeds. Long-chain cyclopropane fatty acids have been described in various polar lipid classes of leaves of early spring plants, whereas both cyclopropane and cyclopropene fatty acids were found in root, leaf, stem, and callus tissue in plants of the Malvaceae [9].

The presence of CPFA has also been documented in some aquatic invertebrates, marine isolates $[24,25]$ and in the lipid composition of mushrooms, mainly belonging to the family Boletaceae [15]. Overall, the natural distribution of CPFA among eukaryotes appears much less common than among bacteria.

\subsubsection{Biosynthesis and physiological aspects}

CPFA synthesis involves the transfer of a methylene group from S-adenosyl methionine by the CPFA synthase to the cis double bond of the precursor unsaturated fatty acids, already integrated into phospholipids of cellular membrane [5]. A proposed pathway for the biosynthesis of dihydrosterculic acid from oleic acid is shown in Figure 2.

The reaction is a post synthetic modification and has been widely studied in microorganisms such as E. coli [26-29], Pseudomonas, Mycobacterium, Lactobacillus spp. and Leishmania spp. [20, 30, 31].

Cyclopropane fatty acids are not essential fatty acids, but the bacterial production of cyclopropane ring seems to be related to changes in the membrane fatty acid composition of that microorganisms. In fact, the presence of these specific fatty acids seems to favor the stress tolerance of several bacteria strains to adverse environments (including ethanol, osmotic and oxidative stress, hot temperature, and low $\mathrm{pH}$ ) and likely plays a role in the pathogenesis of bacterial infections [32].

The acid tolerance of individual strains of E. coli appears to be correlated with membrane cyclopropane fatty acid content and may enhance the survival of microbial cells exposed to low $\mathrm{pH}$ [29]. During acid habituation, monounsaturated fatty acids (cis-16:1 and cis-18:1) are either converted to their cyclopropane derivatives or replaced by saturated fatty acids. On the contrary, E. coli mutants deficient in CPFA seemed to be more sensitive to adverse conditions such as repeated freeze-drying and pressure [33].

Natural CPFA occur widespread with a cis configuration about cyclopropane moiety [5]; however, trans cyclopropane fatty acids are common in the cell

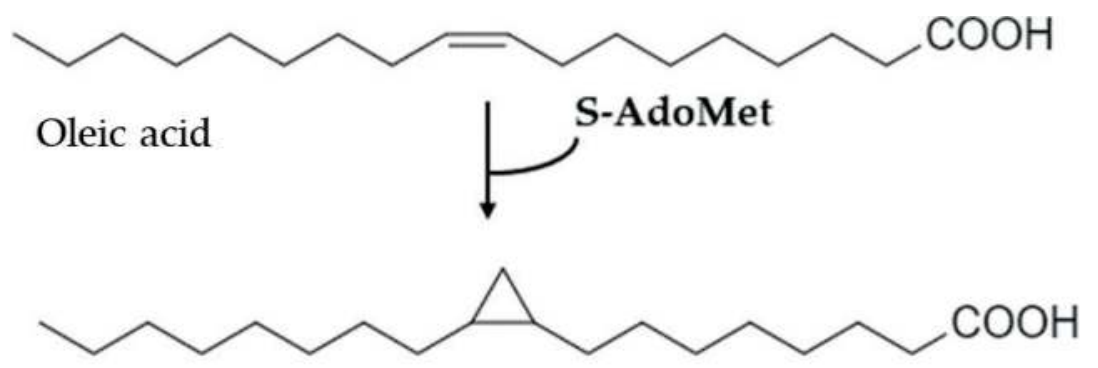

\section{Dihydrosterculic acid}

Figure 2.

Biosynthesis of dihydrosterculic acid from oleic acid by CPFA synthase. 
envelope of Mycobacterium tuberculosis and play a role in regulating virulence. Cyclopropanation of mycolic acids has been suggested to be correlated with the persistence of the pathogen and modulates the innate immune response of the host $[34,35]$.

Cyclopropane fatty acids tend to promote the fluidity of lipid bilayers by interfering with lipid packing, improving the formation of gauche defects originating partly from the steric restraints caused by the methylene moieties and increasing lipid diffusion [31]. This could explain how cyclopropane fatty acids can improve the stability of the membrane against adverse conditions and, at the same time, reduce its permeability against toxic compounds.

CPFA are cellular components of lactic acid bacteria (LAB), such as Lactobacillus bulgaricus, L. helveticus, L. sanfranciscensis, and L. acidophilus, and are synthetized to strength their membrane, improving their resistance to unfavorable conditions to which $\mathrm{LAB}$ are exposed during their proliferation and lactic fermentation in foods as well as the response to osmotic and ethanol stresses [30].

Recently, we reported the presence of CPFA in ensiled feeds (as maize silage) and in milk and cheeses from cow fed with silages $[10,11]$. Some LAB strains, both homofermentative such as Lactobacillus plantarum and heterofermentative (i.e., Lactobacillus buchneri and Lactobacillus brevis), are known to represent major constituents of the microbial ecosystem in silages [36]. Crop ensiling technology is based on the natural fermentation of plant tissue juice mediated by the lactic acid bacteria naturally present in the plant leaves. LAB convert soluble carbohydrates to organic acids, mainly lactic acid, under anaerobic conditions, resulting in a $\mathrm{pH}$ drop from 6.0-6.5 to 5.0-3.7 [36]. Therefore, the presence of CPFA in milk was related to their presence in ensiled products, where they are released by bacteria during silage fermentation conditions. Further studies on dairy products [10] demonstrated that $\mathrm{LAB}$, ubiquitous in fermented milk and cheeses, were not able to release significant amount of CPFA in the medium during milk fermentation, and their presence in fermented milk products derives only from their starting content in milk.

\subsection{Omega-cyclohexyl fatty acids}

Omega-cyclohexyl fatty acids (CHFAs), as 11-cyclohexyl undecanoic and 13-tridecanoic acids (Figure 3), occur in several acido-thermophilic bacteria, mainly in Alicyclobacillus acidocaldarius $[8,37,38]$.

Cyclohexanecarboxylic acid starter unit in omega-cyclohexyl fatty acid synthesis is derived from shikimic acid, and it is probably related to glucose metabolism [37].

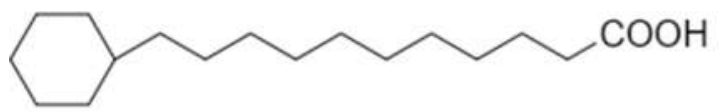

\section{1-cyclohexylundecanoic acid}

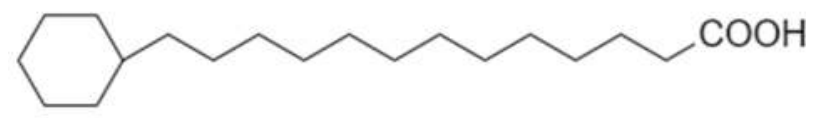

\section{3-cyclohexytridecanoic acid}

Figure 3.

Chemical structure of 11-cyclohexylundecanoic and 13-cyclohexytridecanoic acids. 
In the following paragraph, information about the distribution of omegacyclohexyl fatty acids, their biosynthesis, and their role on the cellular membrane will be provided.

\subsubsection{Distribution and structure}

Omega-cyclohexyl fatty acids are the principal lipid component of saponifiable fraction of Alicyclobacillus acidocaldarius. They also occur in thermoacidophile strains, such as $A$. acidoterrestis and $A$. cycloheptanicus, and in the mesophile Curtobacterium pusillum, where the percentage concentration of these fatty acids in the cellular membrane increases at $\mathrm{pH}$ 3-4 as well as at elevated temperatures $[8,37]$. In fact, omega-cyclic fatty acids are suggested to have special physiological importance for the cells both at hot temperature and acid $\mathrm{pH}$. Model membranes, consisting of lipids containing omega-cyclohexyl fatty acids, are relatively dense and closely packed even at the phase transition temperature [8].

The occurrence of a fully saturated and monosubstituted cyclohexane ring is rare but derivatives of cyclohexyl acid, precursor of omega-cyclohexyl fatty acid biosynthesis, have been isolated from the extract soil and shoots of Achyranthes aspera and from several Streptomyces antibiotics, including ansatrienin A synthetized by $S$. collinus [8]. However, in this case, omega-cyclohexyl fatty acids do not seem to play a similar membrane stabilizing role as in $A$. acidocaldarius.

In eukaryotes, the identification of 11-cyclohexylundecanoic fatty acid has been documented as a minor component of butter fat [40], then in sheep fat $(0.05 \%$ of the total weight of fatty acids) [39] and more recently in cow milk [11]. In this previous work [11], they focused on the identification and characterization of cyclic fatty acids in cow milk to study the effect of diverse types of dairy diet on milk fat composition. 13-cyclohexyl tridecanoic acid methyl ester was well detectable in all milk samples by GC-MS analysis of fatty acid methyl esters (FAME), and its presence was confirmed by mass spectra and the synthetized standard.

The presence of omega-cyclic fatty acids in milk could be related to acidic ruminal fermentation patterns. An increase in starch as well as a decrease of less digestible fiber content favors the growth of amylolytic bacteria. This leads to an increased concentration of rumen volatile fatty acids such as butyric and propionic acids, a decrease of rumen odd and branched fatty acids [41] and lactate accumulation, resulting in a $\mathrm{pH}$ drop, which favors not only the development of the subacute ruminal acidosis (SARA) [42] but also the growth of thermo-acidophilus bacteria, which produce omega-cyclohexyl fatty acids. In this context, the presence of omega-cyclohexyl fatty acids in milk, especially 11-cyclohexylundecanoic and 13-cyclohexyltridecanoic acids, could be represented as a parameter to detect SARA, as proposed by other authors for odd- and branched-chain fatty acids [41]. However, this hypothesis has never been confirmed by experimental data.

\subsection{Cyclic fatty acids in human nutrition}

Cyclic fatty acids are generally secondary compounds in fatty acid profiles of food; however, due to the recent discovery, some gaps of knowledge must be fulfilled. In some cases, especially cyclopropane fatty acids, they could reach the g/ $\mathrm{kg}$ of total fat content in meat and dairy products [12, 43] and their dietary intake may be not negligible.

Therefore, it would be interesting to investigate on their metabolism in humans and eventual physiological effects, considering that bacteria produce cyclic fatty acids to enforce their membranes. The aim of these studies is to achieve a first never reported picture of the occurrence of CPFA in humans and their possible health effects. 
In the following paragraphs, we focused on the investigation of CPFA content in foods to estimate their dietary intake and on their potential bioaccessibility in humans. Finally, a review of literature data about their potential biological effects on mammals will be provided.

\subsubsection{Cyclopropane fatty acids presence in food}

Data reported on CPFA, mainly in dairy products, meat, and fish, were obtained in previous publications [10-12]. The content of cyclopropane fatty acids has also been evaluated in other food categories such as probiotic food supplements, vegetable edible oils (e.g., extra virgin olive, corn, soy, and peanuts oils) and cocoa butter, soy-derived products, and mushrooms (data not published). CPFA content in food categories, resulted positive in previous analysis, is shown in Table 1.

Results showed that among all the analyzed food categories, the most important CPFA food source is Grana Padano cheese, reaching concentration levels of $1 \mathrm{~g} /$ $\mathrm{kg}$ total fat (Table 1). CPFA were detected not only in commercial bovine meat (200-400 mg/kg total fat) but also in some species of fish (eels and mullets) with concentrations between 400 and $800 \mathrm{mg} / \mathrm{kg}$ total fat [12], probiotics, and in mushrooms (data not published). On the contrary, poultry, pork meat, vegetable oils commonly consumed (e.g., extra virgin olive, corn, soy, and peanuts oils), and cocoa butter were all negative to CPFA (data not shown), indicating that CPFA presence in foodstuffs of animal origin is correlated with the use of silages in the animal feedings, whereas plant organisms generally do not produce CPFA. As a whole, our results demonstrate the bacterial and fungal origin of CPFA in foods $[16,44]$. Finally, the estimated daily, weekly and monthly CPFA dietary intake in the total Italian population (all sex and ages) [45] resulted in the milligrams order, so not negligible in view of a possible physiological action by CPFA on humans. Furthermore, food processing, manufacturing, seasoning steps, and fermentation [10] seemed not to affect CPFA content in the analyzed food matrices. Certainly,

\begin{tabular}{|c|c|c|c|}
\hline Food & $\begin{array}{c}\text { No. of positive samples } \\
\text { to } \mathrm{CPFA}^{2} / \text { tot }\end{array}$ & $\begin{array}{c}\text { Mean } \pm \mathrm{SD}(\mathrm{mg} / \\
\text { kg total fat })\end{array}$ & $\begin{array}{l}\text { Range (mg/ } \\
\text { kg total fat) }\end{array}$ \\
\hline \multicolumn{4}{|l|}{ Dairy products ${ }^{1}$} \\
\hline Cow milk & $49 / 50$ & $310 \pm 240$ & $70-830$ \\
\hline Grana Padano (Lombardy, Italy) & $72 / 72$ & $540 \pm 110$ & $300-1000$ \\
\hline Other cow cheeses & $30 / 79$ & $360 \pm 180$ & $180-1000$ \\
\hline Commercial butter & $6 / 10$ & $200 \pm 100$ & $90-335$ \\
\hline Yoghurt/fermented cow milk & $4 / 4$ & $200 \pm 20$ & $170-240$ \\
\hline \multicolumn{4}{|l|}{ Meat $^{1}$} \\
\hline Commercial beef meat & $5 / 5$ & $200 \pm 100$ & $200-400$ \\
\hline \multicolumn{4}{|l|}{ Fish $^{1}$} \\
\hline Eel & $2 / 2$ & $500 \pm 250$ & $400-590$ \\
\hline Mullet & $1 / 1$ & $700 \pm 100$ & $600-800$ \\
\hline \multicolumn{4}{|c|}{${ }^{1}$ Results obtained combining previous analysis [10-12, 43]. } \\
\hline \multicolumn{4}{|c|}{$\begin{array}{l}{ }^{2} C P F A=\text { cyclopropane fatty acids as the sum of total isomers (dihydrosterculic and lactobacillic acids) as reported by } \\
\text { Caligiani et al. [43]. } \\
\text { SD = standard deviation. }\end{array}$} \\
\hline
\end{tabular}

Table 1.

CPFA food sources. 
CPFA can be considered unknown components of the human diet, and additional information about their possible impact on humans is useful to provide a further understanding on the link between diet and human health.

\subsubsection{CPFA digestibility and potential bioaccessibility}

Triglycerides (TG) are the major components of dietary fats, and once ingested, they are submitted to a hydrolytic process catalyzed by lipases present in gastric and especially in duodenal digestive juices [46]. Nowadays, the evolution of the triglycerides during digestion is a subject of great interest in lipid research, as much as the development of methodologies able to evaluate both qualitatively and quantitatively all the products generated from this process [13].

As reported in the previous paragraphs, no information is present in literature about the fate of CPFA within the human body, and a thorough investigation of how CPFA accumulate and are metabolized in humans is needed. In [13], the rate of CPFA digestibility has been assessed through their lipolysis and resistance to in vitro simulated human gastrointestinal (GI) digestion in Grana Padano cheese, one of the most relevant sources of CPFA [43]. Results showed a high percentage of digestibility of the lipid fraction (more than $90 \%$ of free fatty acids and 1-monoglycerides were obtained after digestion). Furthermore, CPFA were all released from TG and the cyclopropane ring was not degraded, proving its resistance to GI digestion, mainly due to the acid $\mathrm{pH}$ of the gastric environment. Results of CPFA concentration in fat before and after in vitro digestion are reported in Table 2.

These observations are encouraging, since CPFA seemed to be potentially efficiently absorbable and, ideally, bioavailable. Certainly, additional research is needed to evaluate the diffusion of these unusual fatty acids through the membrane of the small intestine epithelial cells as well as their presence in human plasma. For this purpose, an in vivo study needs to be conducted to determine the eventual CPFA presence in human plasma after a CPFA-rich diet.

\subsubsection{Potential biological effects of cyclic fatty acids}

Cyclopropane and omega-cyclohexyl fatty acids play a significant role in increasing the chemical and physical stability of bacterial membranes to adverse conditions [8]. To the best of our knowledge, little information is reported in literature about the effect of cyclic fatty acids in higher animals. However, some papers concern about biological activity of cyclopropene fatty acids, mainly sterculic acid, in mammals [9, 47-49]. On the contrary, omega-cyclic fatty acids remain an under investigated lipid class from a nutritional and physiological significance.

Many seed lipids containing cyclopropene fatty acids are extensively consumed by humans, especially in tropical areas [9]. It has been documented that their dietary leads to the accumulation of hard fats and other physiological disorders in animals [9].

Some studies suggested the effect of sterculic acid on lipid metabolism in mammals, especially in dairy sheep [47] and in human Caco2 cells [48], as inhibitor of $\Delta 9$-desaturase, which has a key role in the endogenous synthesis of cis-9, trans-11 conjugated linoleic acid (rumenic acid), known to have interesting properties in improving human health.

It is also known that sterculic acid is a potent inhibitor of stearoyl-CoA desaturase (SCD) involved in the biosynthesis of monounsaturated fatty acids (MUFA). SCD catalyzes the NADH- and $\mathrm{O}_{2}$-dependent desaturation of palmitate (16:0) and 


\begin{tabular}{lcc}
\hline \multicolumn{1}{c}{ Lipid classes } & CPFA before digestion & CPFA after digestion \\
\hline TG & $540 \pm 20 \mathrm{mg} / \mathrm{kg}$ & $\leq \mathrm{LOD}(60 \mathrm{mg} / \mathrm{kg})$ \\
\hline FFA and MG & $\leq \mathrm{LOD}(60 \mathrm{mg} / \mathrm{kg})$ & $520 \pm 10 \mathrm{mg} / \mathrm{kg}$ \\
\hline $\begin{array}{l}\text { Results are expressed in } \mathrm{mg} / \mathrm{kg} \text { of total extracted fat as mean } \pm \text { standard deviation. } F F A, \text { free fatty acids; } M G, \\
\text { monoglycerides; TG, triglycerides. Cyclopropane fatty acids (CPFA) refer to the sum of dihydrosterculic and } \\
\text { lactobacillic acids [13]. }\end{array}$ & \\
\hline
\end{tabular}

Table 2.

Free (as FFA and MG) and bound (as TG) CPFA in Grana Padano cheese before and after in vitro simulated human GI digestion.

stearate (18:0) at carbon 9 to produce palmitoleate (cis-9, 16:1) and oleate (cis-9, 18:1), respectively, and has a crucial role in regulation of adipocyte proliferation/ differentiation of adipocytes, mainly in ruminant species $[49,50]$. Due to the structural analogies between cyclopropene and cyclopropane fatty acids, it is possible to hypothesize a possible physiological role for CPFA in lipid metabolism as well.

Fatty acids (FA) with a cyclopropane in the structure, especially cyclopropaneoctanoic acid 2-hexyl (CPA2H), have also been recently identified in human serum and adipose tissue of obese patients $[32,51]$ suggesting that they are absorbed as the other fatty acids and can be selected markers of metabolic disorders such as dyslipidemia, inflammation, and increased cardiovascular risk. These studies reported that both obese patients with hypertriglyceridemia and non-obese patients with chronic kidney disease (CKD) presented elevated serum levels of $\mathrm{CPA} 2 \mathrm{H}$, suggesting a positive correlation between high serum levels of $\mathrm{CPA} 2 \mathrm{H}$ and high serum TG and cholesterol concentrations rather than to body mass or body mass index (BMI). These results show that $\mathrm{CPA} 2 \mathrm{H}$ negatively affect the cellular lipid metabolism; however, the relevance of altered serum concentrations of this fatty acid remains still unclear.

Previously, it has been reported that cyclopropane fatty acids can influence the pathogenicity of Mycobacterium tuberculosis, demonstrating they could modulate the host immune response $[34,35]$.

TNF is an inflammatory cytokine produced by activated macrophages and plays a key role as a mediator of intestinal inflammation [52]. In [52], they studied select strains of human-derived Lactobacillus reuteri, which are involved in human TNF immunomodulatory activity in gut. This work showed that the bacterial enzyme cyclopropane fatty acid synthase is involved in the anti-inflammatory effect of select strains of $L$. reuteri. Indeed, only the strains contained a cyclopropane fatty acid, lactobacillic acid, were able to inhibit TNF in activated macrophages, whereas cyclopropane fatty acid synthase mutants (lacking cyclopropane fatty acid synthase activity) do not suppress the production of the proinflammatory cytokine. However, lactobacillic acid seemed not to be responsible for mediating the repression of human TNF production, indicating that lactobacillic acid indirectly contributed to $L$. reuteri immunomodulatory activity, probably altering the composition and permeability of bacterial membrane, resulting in a decrease of the membrane fluidity or in an altered expression of immunomodulins.

Since significative amount of dihydrosterculic acid had been found in foods, mainly in dairy products, this fatty acid can be considered a new as well as unknown component of human diet. However, no specific works both in vitro and in vivo about the effect of dihydrosterculic acid are available in the literature, for example on enzyme activity, cellular membranes, and metabolism in mammals.

Future studies should elucidate how and whether this uncommon FA may have a biological role and clarify its healthy or unhealthy effects in humans. 


\subsection{Cyclic fatty acids in food authentication}

In the last decades, food frauds have been on the rise [53]. For this reason, food authentication represents an important strategic issue for food industry because consumers are becoming increasingly interested in the quality and origin of foods. This is especially true when consumers purchase expensive certified and high added-value products, such as protected denomination of origin (PDO) or protected geographical indication (PGI) products [54].

Assuring food authenticity is not only an economical issue for food industries but it also concerns consumer safety, due to the substitution of food grade materials by cheaper non-food grade materials or to the presence of undeclared ingredients. The broad objective in food authentication is to identify unique or groups of markers to characterize the authenticity of food or their potential adulterants/contaminants and use them to resolve authenticity problem $[55,56]$.

As previously reported, cyclopropane and $\omega$-cyclohexyl fatty acids, isolated respectively in lactic and rumen bacteria, have been identified in milk and dairy products as well as in meat. The occurrence and the content of cyclopropyl fatty acids in dairy products and meat were mainly correlated with the presence in forage of maize silage, whereas omega-cyclohexyl fatty acids have been proposed as marker of species, especially for ruminant species. In the following paragraphs, we will focus on the role of cyclic fatty acids as quality markers in food authentication mainly in dairy products and meat.

\subsubsection{Cyclopropane fatty acids as quality markers in dairy products}

In dairy sector, the most critical issue in authentication is related to PDO cheeses, which are high commercial value products confined according to legislative and proper labeling rules. The higher prices of PDO products encourage more frequent food fraud [57]. Their authenticity is associated with several factors, such as the geographical area of production, materials, and technology used. In fact, cheese production can differ according to the feeding system of the animals providing all the ingredients as milk, the starters used, and the presence or lack of preservatives as well as other parameters (i.e., the heating temperature, the salting, the ripening time). All of these generate defined characteristics, which in turn can be detected by several analytical techniques, and provide a trace of the cheese origin [58,59].

Among PDO cheeses, Parmigiano-Reggiano is probably the most worldwide appreciated Italian PDO cheese. It represents a fully natural high-quality cheese only made in a very small and specific region of Italy, without the use of additives and from milk of local cows fed with hay and not silage as fodder commonly used worldwide in livestock feeding. It is made according to the Production Specification Rules laid down by Parmigiano-Reggiano Cheese Consortium (CFPR) according to EU regulations (EU 510/2006 and following 1151/12). Due to the high quality of the raw material, the long ripening, and the strict rules of production, it is an expensive cheese, but despite this, a constant growing of the national and international market is registered [60]. Consequently, the problem of fraud is a critical issue. In fact, several grated varieties branded as Parmesan and with "Italian sound" elements on the pack were found to be inauthentic, some of them containing non-declared additives. Therefore, mislabeling is a severe problem concerning unfair competition and deception to the detriment of consumers.

As previously reported, data collected by the authors $[10,11,43]$ on hundreds of milk and dairy samples confirm the strict correlation between the use of silages in the feeding and the presence of CPFA in milk fat. Cyclopropane fatty acids (CPFA) were present only in dairy products from cows fed with silages, and their 
determination has been demonstrated to be molecular markers of quality for PDO cheeses, as Parmigiano-Reggiano, where the use of silage is forbidden [10]. In this context, an example of successful case was the innovative method (UNI11650) that has been developed for Parmigiano-Reggiano cheese authentication based on the presence or absence of CPFA [43]. As results, Grana Padano (GP) samples were always positive to CPFA, reflecting that silages are not forbidden for their production (Figure 4). The amount of CPFA found in Grana Padano is variable, and it ranges from 300 to $830 \mathrm{mg} / \mathrm{kg}$ of fat, with a global mean value of $540 \pm 110 \mathrm{mg} / \mathrm{kg}$ [43].

Because grated parmesan is particularly vulnerable to being adulterated with other cheeses, mix of Parmigiano-Reggiano with a cheese produced with milk from ensiled-fed cows have been analyzed to establish the minimum level of adulteration. The GC-MS method [43] was able to detect frauds that included $10-20 \%$ of cheaper cheeses. Adulteration behind this value has scarce commercial significance. Furthermore, the optimized GC-MS method was subjected to validation in terms of precision, accuracy, linearity, detection, and quantitation limits following the recommendations of the International Conference on Harmonization [61]. Therefore, due to the innovative and encouraging results, an application for an official standardization of the method (UNI method 11650) has been validated and included in Parmigiano-Reggiano Product Specification Rules among the official controls, enforcing the current analytical methods adopted for the quality controls.

In conclusion, the presence of CPFA in milk and dairy products probably derives from their presence in ensiled feeds, where CPFA can be released by bacteria during fermentation. The environmental conditions developed in silos seem to be essential for the production and release of CPFA from bacteria, whereas shelf-life, manufacturing, seasoning steps, and lactic fermentation did not affect CPFA content [11]. As a whole, CPFA demonstrated to be interesting molecular markers, able to distinguish cheeses obtained from cows fed with or without silages. Moreover, the

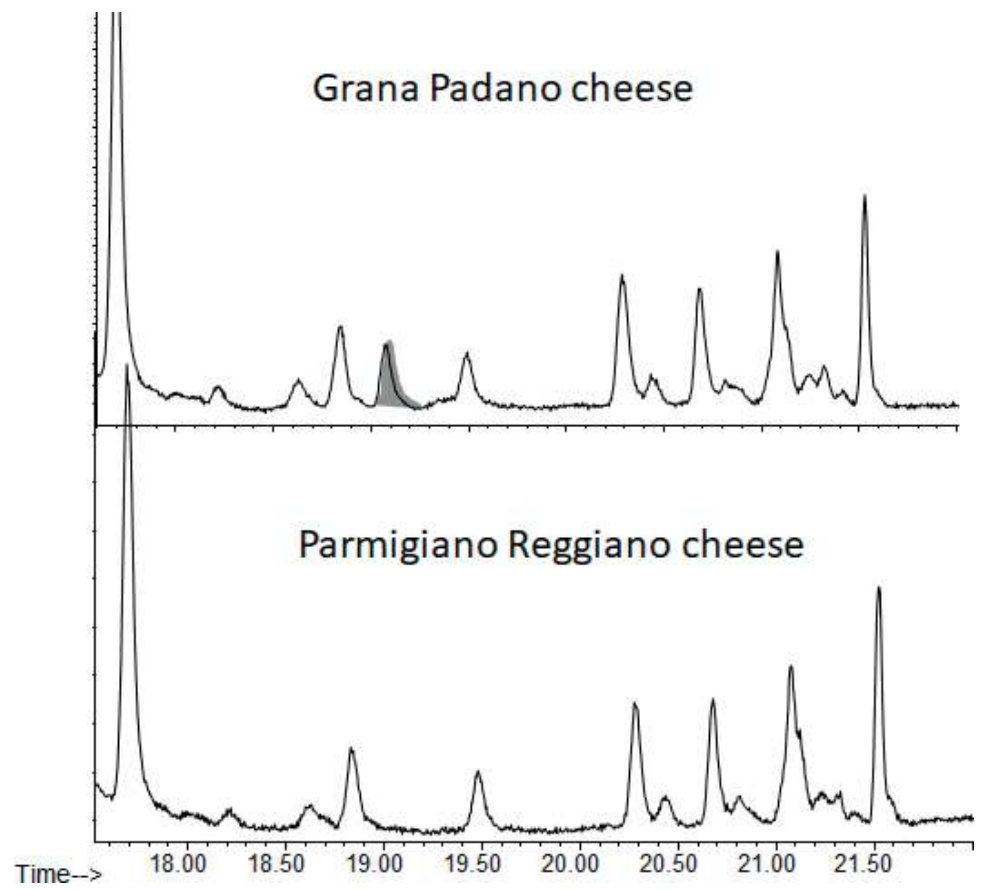

Figure 4 .

Enlarged view of CPFA peak elution zone and comparison between a sample of Grana Padano cheese positive to CPFA and a sample of Parmigiano-Reggiano cheese negative to CPFA [43]. 
quantitative GC-MS method developed is relatively simple, assures a quick sample preparation, and relies on available instrumentation, thus making it suitable for the screening of many samples with a good cost-per-analysis ratio.

\subsubsection{Cyclic fatty acids as quality markers in meat}

An increasing critical issue is the substitution of higher commercial valued meats by low-priced ones and the fraudulent labeling of meat species [62]. In this context, there is the need for new, fast, and reliable analytical methodologies and easily quantifiable markers to be used for meat authentication and to protect both consumers and producers from illegal substitutions. Current methods to identify the origin of species present in commercial meat are based on DNA and ELISA, but also UPLC, Raman spectroscopy, low-field NMR, and mass spectrometry have been considered [63].

Fatty acids in food authentication were mainly used for the determination of the cow feeding system, which affect the milk and meat fat composition $[64,65]$. Previously, many data have been collected confirming the association between the use of ensiled feeds and the presence of CPFA in the fatty profile of dairy products.

As suggested by Lolli et al. [12], cyclopropane fatty acids (mainly dihydrosterculic acid) have also been detected in animal fat, especially in bovine meat fat. As results, CPFA were detected in the fatty profiles of commercial bovine meat samples but they were absent in the samples of certified meat from cows not fed with fermented forages, reflecting the same correlation observed in dairy products $[10,11,43]$. In the case of meat of other animal species (pork, pork cured meat, and chicken), results did not show the presence of cyclopropane fatty acids as shown in Table 3. These preliminary results suggested that CPFA might be proposed as markers of silage feedings and for the authentication of high quality costly meat whose producers declare the absence of silages in the feeding as in dairy products. Certainly, it will require the construction of a robust database of certificated meat for the feeding system. Moreover, CPFA (mainly lactobacillic acid) were recently found [12] in farmed fish. Therefore, this approach could also be extended to fish to eventually distinguish farmed from wild fish.

Regarding omega-cyclohexyl fatty acids, they have been detected [11] (mainly 11-cyclohexyl undecanoic and 13-cyclohexyl tridecanoic fatty acids) in the GC-MS fatty profile of cow milk, suggesting their presence in milk fat could represent a reliable method to evidence rumen acidosis in cows. However, as mentioned above, this hypothesis has never been confirmed by experimental data.

Recently, they have been also identified in animal fat, mainly in meat of ruminants, especially bovine and ovine meat [14]. Preliminary data (not published) showed that omega-cyclohexyl fatty acids, combined with other fatty acids as branched chain fatty acids [41], permitted to discriminate beef from pork meat.

\begin{tabular}{lcc}
\hline Sample of meat & $\begin{array}{c}\mathbf{N}^{\circ} \\
\text { sample }\end{array}$ & $\begin{array}{c}\text { Range CPFA (mg/kg total } \\
\text { fat) }\end{array}$ \\
\hline Commercial bovine meat & 5 & $200-400$ \\
\hline Bovine meat of certified origin (not fed with silages) & 2 & Negative $^{\mathrm{a}}$ \\
\hline Other meats (pork and chicken) & 4 & Negative $^{\mathrm{a}}$ \\
\hline Pork cured meat & 3 & Negative $^{\mathrm{a}}$ \\
\hline${ }^{a}<L O D(60 \mathrm{mg} / \mathrm{kg}$ total fat) [12]. & & \\
\hline
\end{tabular}

Table 3.

Presence of CPFA in meat samples. 
As suggested by Marseglia et al. [11], 11-cyclohexyl undecanoic fatty acid methyl ester from milk and meat fat eluted in the chromatographic region of isomers of the oleic acid, so it was detected by the characteristic molecular ion $282 \mathrm{~m} / \mathrm{z}$ in the mass spectrum.

13-cyclohexyl tridecanoic fatty acid methyl ester was detectable in the GC-MS profile as it elutes just before the eicosanoic acid (arachidic acid) and after eicosenoic acid. However, due to the presence of interfering signals, the identification of 13-cyclohexyl tridecanoic was confirmed by the mass spectrum with the characteristic molecular ion $310 \mathrm{~m} / \mathrm{z}$ and the previous biosynthesized compound [11]. The characteristic mass spectra of 13-cyclohexyl tridecanoic fatty acid detected by GC-MS analysis is shown in Figure 5.

The results from the GC-MS analysis showed that omega-cyclohexyl fatty acids, both 11-cyclohexylundecanoic acid and 13-cyclohexyltridecanoic acid, were present only in bovine and ovine meat samples with values between 90-230 and $20-200 \mathrm{mg} / \mathrm{kg}$ of the total meat fat, respectively [14]. On the contrary, they were absent in pork, horse, chicken, and rabbit, reflecting the ruminal origin and a possible application for the detection of bovine/pork ratio in commercial minced meat [14].

As mentioned above, current analytical methods in meat authentication are mainly based on protein or DNA measurement, which are not directly comparable to labeled meat expressed as percentage (w/w) [66]. Furthermore, analytical procedures based on protein analysis are sensitive to heat treatment. Therefore, they could not be applied to cooked products for the quantitative analysis. In this context, a quantitative GC-MS method is going to be developed on mixtures of beef and pork meat, both raw and cooked (ragout), based on the method previously applied to determine CPFA [43] and combining other fatty acids, as iso-branched chain fatty acids, of ruminal origins [41].

Preliminary results [14] showed that omega-cyclohexyl and iso-branched chain fatty acids content decreased in minced meat, both raw and cooked, as function of bovine meat percentage in the sample, as shown in Table 4.

Therefore, the analysis of omega-cyclohexyl fatty acids combined with that of specific iso-branched chain fatty acids was able to detect until $20 \%$ of pork meat in beef, representing potential markers for ruminant meat, also detectable in complex matrix and after thermal treatment in ragout samples.

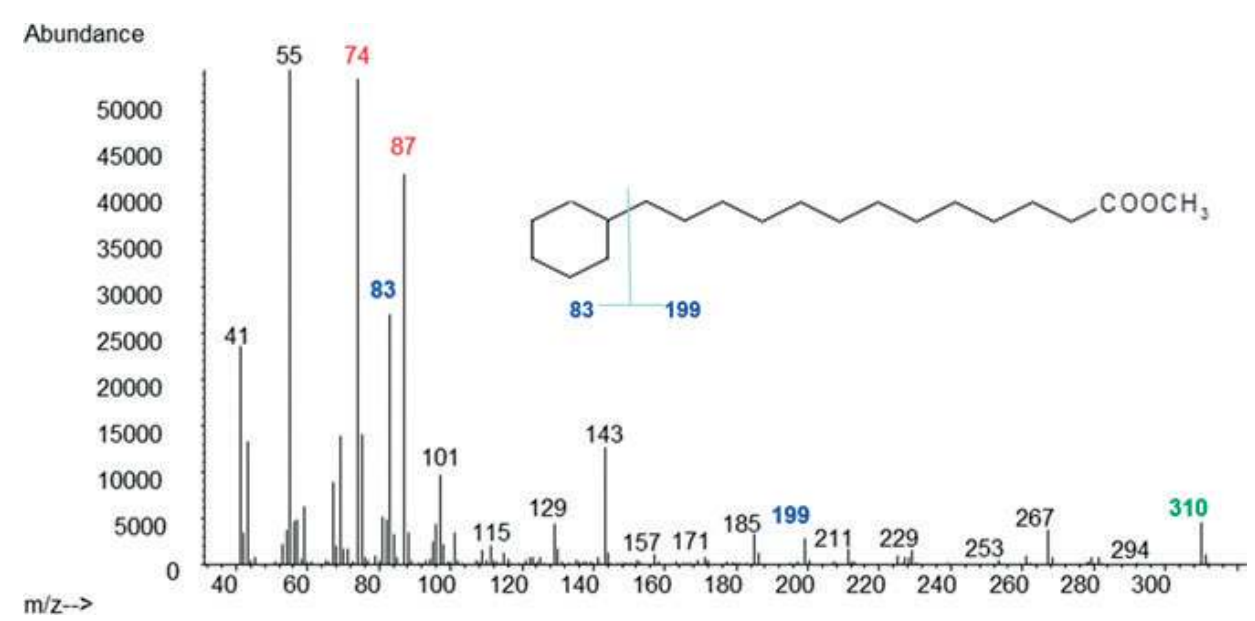

Figure 5.

Mass spectra of 13-cyclohexyl tridecanoic fatty acid methyl ester [11]. 


\begin{tabular}{|c|c|c|c|c|}
\hline $\begin{array}{l}\text { Percentage } \\
\text { of bovine/ } \\
\text { pork in } \\
\text { fresh meat }\end{array}$ & $\begin{array}{c}\text { 11-cyclohexylun } \\
\text { decanoic acid } \\
(\mathrm{mg} / \mathrm{kg})\end{array}$ & $\begin{array}{c}\text { 13-cyclohexyltri } \\
\text { decanoic acid } \\
(\mathrm{mg} / \mathrm{kg})\end{array}$ & $\begin{array}{c}\text { Iso methyl } \\
\text { C16:0 (mg/kg) }\end{array}$ & $\begin{array}{c}\text { Iso methyl C17:0 } \\
(\mathrm{mg} / \mathrm{kg})\end{array}$ \\
\hline 100 bovine & $175 \pm 7$ & $55 \pm 7$ & $1500 \pm 240$ & $2240 \pm 721$ \\
\hline $\begin{array}{l}80 \mathrm{bov} / 20 \\
\text { pork }\end{array}$ & $120 \pm 28$ & $35 \pm 7$ & $1005 \pm 49$ & $1595 \pm 219$ \\
\hline $\begin{array}{l}60 \text { bov/ } 40 \\
\text { pork }\end{array}$ & $40 \pm 1$ & $20 \pm 14$ & $650 \pm 14$ & $1055 \pm 148$ \\
\hline $\begin{array}{l}40 \text { bov/ } 60 \\
\text { pork }\end{array}$ & $20 \pm 1$ & $15 \pm 7$ & $690 \pm 42$ & $860 \pm 283$ \\
\hline $\begin{array}{l}20 \mathrm{bov} / 40 \\
\text { pork }\end{array}$ & $15 \pm 7$ & $5 \pm 7$ & $200 \pm 100$ & $385 \pm 21$ \\
\hline 100 pork & nd & nd & $90 \pm 1$ & $145 \pm 21$ \\
\hline $\begin{array}{l}\text { Percentage } \\
\text { of bovine/ } \\
\text { pork in } \\
\text { ragout }\end{array}$ & $\begin{array}{c}\text { 11-cyclohexylun } \\
\text { decanoic acid } \\
(\mathrm{mg} / \mathrm{kg})\end{array}$ & $\begin{array}{c}\text { 13-cyclohexyltri } \\
\text { decanoic acid } \\
(\mathrm{mg} / \mathrm{kg})\end{array}$ & $\begin{array}{c}\text { Iso methyl } \\
\mathrm{C} 16: 0 \text { (mg/kg) }\end{array}$ & $\begin{array}{c}\text { Iso methyl C17:0 } \\
(\mathrm{mg} / \mathrm{kg})\end{array}$ \\
\hline 100 bovine & $100.0 \pm 10.5$ & $32.5 \pm 1.9$ & $821.7 \pm 79.0$ & $1166.0 \pm 17.0$ \\
\hline $\begin{array}{l}80 \mathrm{bov} / 20 \\
\text { pork }\end{array}$ & $80.0 \pm 5.7$ & $26.5 \pm 0.1$ & $690.8 \pm 61.9$ & $943.4 \pm 125.4$ \\
\hline $\begin{array}{l}60 \mathrm{bov} / 40 \\
\text { pork }\end{array}$ & $40.0 \pm 1.7$ & $11.1 \pm 1.9$ & $381.8 \pm 33.3$ & $539.7 \pm 39.1$ \\
\hline $\begin{array}{l}40 \text { bov/60 } \\
\text { pork }\end{array}$ & $6.8 \pm 5.7$ & nd & $238.9 \pm 2.0$ & $296.6 \pm 20.2$ \\
\hline $\begin{array}{l}20 \mathrm{bov} / 40 \\
\text { pork }\end{array}$ & $5.5 \pm 1.3$ & nd & $202.8 \pm 35.2$ & $233.0 \pm 32.0$ \\
\hline 100 pork & nd & nd & $29.3 \pm 1.9$ & $56.2 \pm 18.9$ \\
\hline
\end{tabular}

Table 4.

Concentration $(\mathrm{mg} / \mathrm{kg}$ total fat) of omega-cyclohexyl and iso-branched chain fatty acids found in minced meat, both raw and cooked (ragout), as function of bovine meat percentage [14].

In conclusion, omega-cyclohexyl fatty acids can be proposed as markers of ruminant meat, especially of beef meat, which could enforce current analytical methods applied for labeling regulations.

\section{Conclusions}

Cyclopropane and omega-cyclohexyl fatty acids are carboalicyclic fatty acids widely distributed among microorganisms, enhancing the chemical and physical stability of bacterial membranes. Significant variations in the membrane content of cyclic fatty acids have been identified in a multitude of physiological situations. Recently, they have been detected in food of animal origins, so representing new components in human diet. In some cases, these cyclic fatty acids can act as markers of quality and their detection could enforce current analytical methods adopted in food authentication.

However, little is known regarding the actual role that these fatty acids play, their release, and the chemical basis of their effects on the cellular membrane, especially in higher animals. 
Cyclic Fatty Acids in Food: An Under-Investigated Class of Fatty Acids

DOI: http://dx.doi.org/10.5772/intechopen.8050o

\section{Conflict of interest}

We declare that we have no conflict of interest.

\section{Author details}

Augusta Caligiani* and Veronica Lolli

Department of Food and Drug, University of Parma, Parma, Italy

*Address all correspondence to: augusta.caligiani@unipr.it

\section{IntechOpen}

(C) 2018 The Author(s). Licensee IntechOpen. This chapter is distributed under the terms of the Creative Commons Attribution License (http://creativecommons.org/licenses/ by/3.0), which permits unrestricted use, distribution, and reproduction in any medium, provided the original work is properly cited. (cc) BY 


\section{References}

[1] Marchello JA. Animal fat composition and modification.

In: Functional Dietary Lipids. Elsevier Inc. 2016. DOI: 10.1016/

B978-1-78242-247-1.00003-X

[2] Zárate R, Jaber-Vazdekis NE, Tejera N, Pérez JA, Rodríguez C. Significance of long chain polyunsaturated fatty acids in human health. Clinical and Translational Medicine. 2017;6:25. DOI: 10.1186/s40169-017-0153-6

[3] Sanders TAB. Introduction: The role of fats in human diet. In: Functional Dietary Lipids. Elsevier Inc. 2016. DOI: 10.1016/B978-1-78242-247-1.00001-6

[4] Rustan AC, Drevon AC. Fatty acids: Structures and properties. In: Encyclopedia of Life Sciences. John Wiley \& Sons, Inc. 2005. pp. 1-7. DOI: 10.1038/npg.els.0003894

[5] Grogan DW, Cronan JE. Cyclopropane ring formation in membrane lipids of bacteria. Microbiology and Molecular Biology Reviews. 1997;61(4):429-441

[6] Kaneda T. Iso- and anteiso-fatty acids in bacteria: Biosynthesis, function, and taxonomic significance. Microbiological Reviews. 1991;55(2):288-302

[7] Tvrzicka E, Kremmyda LS, Stankova B, Zak A. Fatty acids as biocompounds: Their role in human metabolism, health and disease-A review. Part 1: Classification, dietary sources and biological functions. Biomedical Papers of the Medical Faculty of the University Palacky, Olomouc, Czech Republic. 2011;155(2):117-130

[8] Moore BS, Floss HG. Biosynthesis of cyclic fatty acid containing cyclopropyl, cyclopentyl, cyclohexyl and cycloheptyl rings. Reference Module in Chemistry, Molecular Sciences, and Chemical Engineering, from Comprehensive
Natural Products Chemistry. 1999;1:61-82

[9] Bao X, Katz S, Pollard M, John O. Carbocyclic fatty acids in plants: Biochemical and molecular genetic characterization of cyclopropane fatty acid synthesis of Sterculia foetida. Plant Biology. 2002;99(10):7172-7177

[10] Caligiani A, Marseglia A, Palla G. An overview on the presence of cyclopropane fatty acids in milk and dairy products. Journal of Agricultural and Food Chemistry. 2014;62:7828-7832

[11] Marseglia A, Caligiani A, Comino L, Righi F, Quarantelli A, Palla G. Cyclopropyl and $\omega$-cyclohexyl fatty acids as quality markers of cow milk and cheese. Food Chemistry. 2013;140:711-716

[12] Lolli V, Marseglia A, Palla G, Zanardi E, Caligiani A. Determination of cyclopropane fatty acids in food of animal origin by ${ }^{1} \mathrm{HNMR}$. Journal of Analytical Methods in Chemistry. 2018;2018:ID:8034042, 8 pp. DOI: $10.1155 / 2018 / 8034042$

[13] Lolli V, Dall'Asta M, Del Rio D, Caligiani A. In vitro digestibility of cyclopropane fatty acids in grana Padano cheese: A study combining 1H NMR and GC-MS techniques. Journal of Food Engineering. 2018;237:226-230. DOI: 10.1016/j. jfoodeng.2018.05.034

[14] Lolli V, Zanardi E, Marseglia A, Palla G, Caligiani A. Cyclic fatty acids as quality markers in meat. In: FOODINTEGRITY 2017 Assuring the Integrity of the Food Chain: Turning Science into Solutions; 10-11th May 2017; Parma. pp. 178-179

[15] Pedneault K, Angers P, Gosselin A, Tweddell RJ. Fatty acid composition of 
lipids from mushrooms belonging to the family Boletaceae. Mycological Research. 2006;110(Pt 10):1179-1183

[16] Wessjohann LA, Brandt W.

Biosynthesis and metabolism of cyclopropane rings in natural compounds. Chemical Reviews. 2003;103:1625-1647

[17] Hofmann K, Lucas RA, Sax SM. The chemical nature of the fatty acids of Lactobacillus arabinosus. The Journal of Biological Chemistry. 1952;195:473

[18] Wood R, Reiser R. Cyclopropane fatty acid metabolism: Physical and chemical identification of propane ring metabolic products in the adipose tissue. The Journal of the American Oil Chemists' Society. 1965;42:315-320

[19] Aued-Pimentel S, Lago JH, Chaves $\mathrm{MH}$, Kumagai EE. Evaluation of a methylation procedure to determine cyclopropenoids fatty acids from Sterculia striata St. Hil. Et Nauds seed oil. Journal of Chromatography A. 2004;1054(1-2):235-239

[20] Xu W, Mukherjee S, Ning Y, Hsu FF, Zhang K. Cyclopropane fatty acid synthesis affects cell shape and acid resistance in Leishmania mexicana. International Journal for Parasitology. 2018;48(3-4):245-256. DOI: 10.1016/j. ijpara.2017.09.006

[21] Ralaimanarivo A, Gaydou EM, Bianchini JP. Fatty acid composition of seed oils from six Adansonia species with particular reference to cyclopropane and cyclopropene acids. Lipids. 1982;17:1

[22] Gaydou EM, Ralaimanarivo A, Bianchini JP. Cyclopropanoic fatty acids of Litchi (Litchi chinensis) seed oil. A reinvestigation. Journal of Agricultural and Food Chemistry. 1993;41:886-890

[23] Adorée AAR, Blond JP, Cao J, Gaydou EE, Bezàrd J. Influence of cyclopropene fatty acids (Baobab seed oil) feeding on the in vitro A9 desaturatlon of stearlc acid in rat liver microsomes. The Journal of Nutritional Biochemistry. 1993;4:92-96

[24] Fish WR, Holz GG Jr, Beach DH, Owen E, Anekwe GE. The cyclopropane fatty acid of trypanosomatids.

Molecular and Biochemical Parasitology. 1981;3(2):103-115

[25] Rob T, Ogi T, Maarisit W, Taira J, Ueda K. Isolation of C11 compounds and a cyclopropane fatty acid from an Okinawan ascidian, Diplosoma sp. Molecules. 2011;16:9972-9982. DOI: 10.3390/molecules16129972

[26] Cronan JE Jr, Nunn WD, Batchelor JG. Studies on the synthesis of cyclopropane fatty acids in Escherichia coli. Biochimica et Biophysica Acta. 1974;348:63-75

[27] Wang AY, Cronan JE Jr. The growth phase-dependent synthesis of cyclopropane fatty acids in Escherichia coli is the result of an RpoS (KatF)dependent promoter plus enzyme instability. Molecular Microbiology. 1994;11:1009-1017

[28] Rock CO, Jackowski S, Cronan JE Jr. Chapter 2-Lipid metabolism in prokaryotes. Biochemistry of lipids, lipoproteins and membranes. In: Vance DE, Vance JE, editors. New Comprehensive Biochemistry. Vol. 31. 1996. pp. 35-74. DOI: 10.1016/ S0167-7306(08)60509-8

[29] Brown JL, Ross T, Mc Meekin TA, Nichols P. Acid habituation of Escherichia coli and the potential role of cyclopropane fatty acids in low $\mathrm{pH}$ tolerance. International Journal of Microbiology. 1997;37(2-3):163-173

[30] Montanari C, SadoKamdem SL, Serrazanetti DI, Etoa FX, Guerzoni ME. Synthesis of cyclopropane fatty 
acids in Lactobacillus helveticus and Lactobacillus sanfranciscensis and their cellular fatty acids changes following short term acid and cold stresses. Food Microbiology. 2010;27(4):493-502

[31] Poger D, Mark AE. A ring to rule them all: The effect of cyclopropane fatty acids on the fluidity of lipid bilayers. The Journal of Physical Chemistry B. 2015;119(17):5487-5495

[32] Mika A, Stepnowski P, Chmielewski M, Malgorzewicz S, Kaska L, Proczko $M$, et al. Increased serum level of cyclopropaneoctanoic acid 2-hexyl in patients with hypertriglyceridemiarelated disorders. Lipids. 2016;51(7):867-73. DOI: $10.1007 /$ s11745-016-4141-1

[33] Chen YY, Gänzle MG. Influence of cyclopropane fatty acids on heat, high pressure, acid and oxidative resistance in Escherichia coli. International Journal of Food Microbiology. 2016;222:16-22. DOI: 10.1016/j.ijfoodmicro.2016.01.017

[34] Rao V, Fujiwara N, Porcelli SA, Glickman MS. Mycobacterium tuberculosis controls host innate immune activation through cyclopropane modification of a glycolipid effector molecule. The Journal of Experimental Medicine. 2005;201:535-543

[35] Rao V, Gao F, Chen B, Jacobs WR Jr, Glickman MS. Trans-cyclopropanation of mycolic acids on trehalose dimycolate suppresses Mycobacterium tuberculosisinduced inflammation and virulence. The Journal of Clinical Investigation. 2006;116:1660-1667

[36] Muck R. Recent advances in silage microbiology. Agricultural and Food Science. 2013;22(1):3-15

[37] Oshima M, Ariga T. $\Omega$-cyclohexyl fatty acids in acidophilic thermophilic bacteria. The Journal of Biological Chemistry. 1975;250:6963-6968
[38] Siristova L, Luhovy R, Sigler K, Rezanka T. Biosynthesis of $\omega$-alicyclic fatty acids induced by cyclic precursors and change of membrane fluidity in thermophilic bacteria Geobacillus stearothermophilus and Meiothermus ruber. Extremophiles. 2011;15(3):423-429. DOI: $10.1007 / \mathrm{s} 00792-011-0373-4$

[39] Hansen RP, Gerson T. The isolation and identification of 11-cyclohexylundecanoic acid from sheep perinephric fat. Journal of the Science of Food and Agriculture. 1967;18:225-227

[40] Schogct JCM, Begemann $\mathrm{PH}$. Isolation of 11-cyclohexyl undecanoic acid from butter. Journal of Lipid Research. 1965;6:466-470

[41] Fievez V, Colman E, Montoya JC, Stefanov I, Vlaemink B. Milk odd- and branched-chain fatty acids as biomarkers of rumen function-An update. Animal Feed Science and Technology. 2012;172(1-2):51-65

[42] Beauchemin KA, Kreuzer M, O’Mara F, McAllister TA. Nutritional management for enteric methane abatement: A review. Australian Journal of Experimental Agriculture and Animal Husbandry. 2008;48:21-27. DOI: 10.1071/EA07199

[43] Caligiani A, Nocetti M, Lolli V, Marseglia A, Palla G. Development of a quantitative GC-MS method for the detection of cyclopropane fatty acids in cheese as new molecular markers for Parmigiano Reggiano authentication. Journal of Agricultural and Food Chemistry. 2016;64:4158-4164

[44] Liu Y, Srivilai P, Loos S, Aebi M, Kues U. An essential gene for fruiting body initiation in the basidiomycete coprinopsis cinerea is homologous to bacterial cyclopropane fatty acid synthase genes. Genetics. 2006;172:873-884. DOI: 10.1534/genetics.105.045542 
[45] Leclercq C, Arcella D, Piccinelli

$\mathrm{R}$, Sette S, Le Donne C, Turrini

A, et al. The Italian National Food Consumption Survey INRAN-SCAI 2005-06: Main results in terms of food consumption. Public Health Nutrition. 2009;12(12):2504-2532. DOI: 10.1017/ S1368980009005035

[46] Nieva-Echevarría B, Goicoechea E, Manzanos MJ, Guillén MD. A method based on ${ }^{1} \mathrm{HNMR}$ spectral data useful to evaluate the hydrolysis level in complex lipid mixtures. Food Research International. 2014;66:379-387

[47] Bichi E, Toral PG, Hervás G, Frutos P, Gómez-Cortés P, Juárez M, et al. Inhibition of $\Delta 9$-desaturase activity with sterculic acid: Effect on the endogenous synthesis of cis-9 18:1 and cis-9, trans-11 18:2 in dairy sheep. Journal of Dairy Science. 2012;95(9):5242-5252

[48] Schneider AC, Beguine P, Bourez S, Perfield JW, Mignolet E, Debier $\mathrm{C}$, et al. Conversion of t11t13 CLA into c9t11 CLA in Caco-2 cells and inhibition by sterculic oil. PLoS ONE. 2012;7(3):1-8

[49] Gomez FE, Bauman DE, Ntambi JN, Fox BG. Effects of sterculic acid on stearoyl-CoA desaturase in differentiating 3T3-L1 adipocytes. Biochemical and Biophysical Research Communications. 2003;300:316-326

[50] Kadegowda AK, Burns TA, Pratt SL, Duckett SK. Inhibition of stearoylCoA desaturase 1 reduces lipogenesis in primary bovine adipocytes. Lipids. 2013;48:967-976

[51] Sledzinski T, Mika A, Stepnowski P, Proczko-Markuszewska M, Kaska $\mathrm{L}$, Stefaniak T, et al. Identification of cyclopropaneoctanoic acid 2-hexyl in human adipose tissue and serum. Lipids. 2013;48:839-848. DOI: $10.1007 /$ s11745-013-3806-2
[52] Jones SE, Whitehead K, Saulnier D, Thomas CM, Versalovic J, Britton RA. Cyclopropane fatty acid synthase mutants of probiotic human-derived Lactobacillus reuteri are defective in TNF inhibition. Gut Microbes. 2011;2(2):69-79. DOI: 10.4161/gmic.2.2.15282

[53] Bouzembrak Y, Steen B, Neslo R, Linge J, Mojtahed V, HJP M. Development of food fraud media monitoring system based on text mining. Food Control. 2018;93:283-296. DOI: 10.1016/j. foodcont.2018.06.003

[54] Armenta S, de la Guardia M. Analytical approaches for the evaluation of food protected designation of origin. In: Advances in Food Traceability Techniques and Technologies. Elsevier. 2016. pp. 275-301. DOI: $10.1016 /$ B978-0-08-100310-7.00015-6

[55] Mafra I, Ferreira I, Oliveira M. Food authentication by PCR-based methods. European Food Research and Technology. 2008;227(3):649-665. DOI: 10.1007/s00217-007-0782-x

[56] Sébédio JL, Malpuech-Brugère C. Implementation of Foodomics in the food industry. In: Innovation Strategies in the Food Industry. Tools for Implementation. Academic Press. 2016. pp. 251-269. DOI: $10.1016 /$ B978-0-12-803751-5.00013-1

[57] Capuano E, Boerrigter-Eenling R, van der Veer G, van Ruth SM. Analytical authentication of organic products: An overview of markers. Journal of the Science of Food and Agriculture. 2013;93:12-28

[58] Karoui R, De Baerdemaeker J. A review of the analytical methods coupled with chemometric tools for the determination of the quality and identity of dairy products. Food Chemistry. 2007;102:621-640. DOI: 10.1016/j.foodchem.2006.05.042 
[59] Kamal M, Karoui R. Analytical methods coupled with chemometric tools for determining the authenticity and detecting the adulteration of dairy products: A review. Trends in Food Science and Technology. 2015;46:27-48

[60] Italian Dairy Economic Consulting (CLAL). Dairy Market. 2016.

Available from: www.clal.it [Accessed: 2018-06-30]

[61] International Conference Harmonization (ICH). Validation of analytical procedures: Text and methodology. Harmonized Tripartite Guideline. 2005;Q2(R1)

[62] Fajardo V, González I, Martín I, Rojas M, García T, Martín R. A review of current PCR-based methodologies for the authentication of meats from game animal species. Trends in Food Science and Technology. 2010;21:408-421

[63] Watson AD, Gunning Y, Rigby NM, Philo M, Kemsley EK. Meat authentication via multiple reaction monitoring mass spectrometry of myoglobin peptides. Analytical Chemistry. 2015;87(20):10315-10322

[64] Aurousseau B, Bauchart D, Calichon E, Micol D, Priolo A. Effect of grass or concentrate feeding systems and rate of growth on triglyceride and phospholipid and their fatty acids in the $M$. longissimus thoracis of lambs. Meat Science. 2004;66:531-541

[65] Chilliard Y, Ferlay A, Doreau M. Effect of different types of forages, animal fat or marine oils in cow's diet on milk fat secretion and composition especially conjugated linoleic acid (CLA) and polyunsaturated fatty acids. Livestock Production Science. 2001;70:31-48

[66] Ballin NZ, Vogensen FK, Karlsson AH. Species determination-Can we detect and quantify meat adulteration? Meat Science. 2009;83:165-174. DOI: 10.1016/j.meatsci.2009.06.003 